\title{
Investigational Product Transfer Record
}

National Cancer Institute

\section{Source}

National Cancer Institute. Investigational Product Transfer Record. NCI Thesaurus. Code C115568.

Documentation detailing the transfer of an investig ational product (IP) between depots and clinical trial sites, within or across clinical study protocols. 